\title{
THE EFFECT OF HEAT TREATMENT ON MICROSTRUCTURE AND MECHANICAL PROPERTIES OF CAST BAINITIC STEEL USED FOR FROGS IN RAILWAY CROSSOVERS
}

\begin{abstract}
This work deals with the effect of heat treatment on a microstructure and mechanical properties of a selected cast steel assigned as a material used for frogs in railway crossovers. Materials used nowadays in the railway industry for frogs e.g. Hadfield cast steel (GX120Mn13) or wrougth pearlitic steel (eg. R260) do not fulfil all exploitation requirements indicated in the UIC (International Union of Railways) Decision No. 1692/96 in terms of train speed that should be reached on railways. One of the possible solution is using a cast steel with bainitic or bainitic-martensitic microstructure that allows to gain high strength properties the ultimate tensile strength (UTS) of $1400 \mathrm{MPa}$, the tensile yield strength (TYS) of $900 \mathrm{MPa}$ and the hardness of up to 400 BHN. The tested material is considered as an alternative to Hadfield cast steel that is currently used for railway frogs.

Results of an experimental analysis of the effect of conducted heat treatment on a microstructure, the volume fraction of retained austenite and mechanical properties of bainitic steel, are shown in this paper. It was found that, the heat treatment leads to a stabilization of retained austenite in grain boundaries area of the primary austenite. Additionally, the heat treatment according to the variant \#3 results with an almost 3-times higher impact toughness to that exhibited by material subjected to the other treatments.

Keywords: railway crossover, bainitic cast steel, heat treatment, mechanical properties
\end{abstract}

\section{Introduction}

A railway crossover is one of the most important and complex elements of a railway track, not only because of its construction, but also due to its intensive wear. According to the UIC Decision No. 1692/96 it is necessary that the joints between the frog and the rail are made in non-butt joint method in order to achieve a possible increase of train speed up to $200 \mathrm{~km} / \mathrm{h}$ under a pressure on axis not lower than $230 \mathrm{kN}$. Wrought steels with a pearlitic microstructure (e.g. R260) and a Hadfield cast steel (GX120Mn13) are currently used for frogs [1].

Possible ways of a mechanical properties improvement by a heat treatment of materials presently used in the rail transport were described by Korab [2]. The Author [2] concluded that the most efficient improvement method is the heat treatment leading to a formation of martensitic or martenitic/banitic structure that, in turn gives a high strength and hardness of processed materials. On the other hand, it has been reported by Pacyna and Krawczyk [3] that the aforementioned combination of mechanical properties of heat treated rails does not guarantee their good wear properties. Therefore, there is a growing interest in a development of new steels that are more suitable for heavily loaded elements of the railway track. One of the possible candidates are bainitic steels [4-11]. The bainitic steels currently used for frogs are mostly low-alloyed. Their heat treatment includes a normalization annealing at $850 \div 950^{\circ} \mathrm{C}$ followed by a hardening and tempering at
$300 \div 400^{\circ} \mathrm{C}[12,13]$. As described by Green et al. [14] the wear resistance of bainitic cast steels depends on the temperature of isothermal transformation and tempering conditions, whereas the prior normalizing is indispensable for preparing the material to welding [15]. It is worth noted, that using of currently available CCT diagrams allows obtaining the bainitic microstructure across the cast frog with a negligible amount of retained austenite [15]. Nevertheless, there is a lack of a compressive study on the effect of heat treatment on the evolution of microstructure and related mechanical properties in bainitic cast steel designed for the frogs in railway crossovers. Therefore, a filling of this gap has become the main motivation of the presented work.

\section{Experimental procedure}

A $50 \mathrm{~kg}$ bainitic steel ingot, with dimensions of $100 \times 100$ $\times 5000 \mathrm{~mm}$, was provided by the Foundry Research Institute in Krakow in the as-cast condition. Its chemical composition is presented in Table 1.

TABLE 1

The chemical composition of the bainitic cast steel (wt. \%)

\begin{tabular}{|c|c|c|c|c|c|c|c|c|}
\hline \hline $\mathbf{C}$ & $\mathbf{M n}$ & $\mathbf{S i}$ & $\mathbf{P}$ & $\mathbf{S}$ & $\mathbf{C r}$ & $\mathbf{N i}$ & $\mathbf{M o}$ & $\mathbf{T i}$ \\
\hline 0.17 & 0.57 & 0.28 & 0.014 & 0.013 & 1.70 & 2.60 & 0.46 & 0.03 \\
\hline
\end{tabular}

\footnotetext{
* CRACOW UNIVERSITY OF TECHNOLOGY, FACULTY OF MECHANICAL ENGINEERING, 24 WARSZAWSKA STR., 31 -155 KRAKOW, POLAND
}

\# Corresponding author: slawomir.parzych@mech.pk.edu.pl 
The ingot was cut into smaller pieces perpendicular to its longer edge and then the specimens were cut out parallel to the side surface of the ingot. Based on previously described [15] results of our dilatometric analyses, critical temperatures were set as follows: $A c_{1 s}=690^{\circ} \mathrm{C}, A c_{1 f}=760^{\circ} \mathrm{C}$ and $A c_{3}=850^{\circ} \mathrm{C}$ and then the normalizing process was designed [15] Three different variants of the heat treatment (schematically represented in Fig. 1) were applied. The variant \#1 includes only the normalization annealing at $930^{\circ} \mathrm{C}$, while the variant $\# 2$ and variant $\# 3$ were also consisted of $1 \mathrm{~h}$ tempering (at $350^{\circ} \mathrm{C}$ and $650^{\circ} \mathrm{C}$, respectively) after the normalization.

A microstructure evaluation was performed using Leica DMLM light microscope. The volume fraction of retained austenite was measured by X-ray diffraction (XRD) technique by using Tur-M61 HZG4 diffractometer (CoK $\alpha 1$ radiation ( $\lambda=1.7890 \AA$ ) was applied). The hardness of heat treated specimens were measured using the Vickers pyramid indenter and

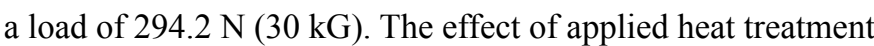

on mechanical properties of the tested material was examined in static tensile tests and Charpy impact tests (initial energy of $150 \mathrm{~J})$. The static tensile tests were carried out on standard bone shaped samples with gauge length of by using MTS810 testing machine. The Charpy tests were performed on ISO Charpy $\mathrm{V}-10$ samples with dimensions of $10 \times 10 \times 55 \mathrm{~mm}$. The fracture toughness of steel samples was tested by using a linear-elastic fracture mechanics measurements based on the stress intensity factor $K_{I c}$ or crack resistance factor $K_{Q}$ in the static bending test in accordance with EN ISO 12737 standard. The sample used in the fracture toughness measurements had dimensions of $10 \times 20 \times 100 \mathrm{~mm}$ with a of slit at the bottom of the prepared notches. The initial slit length was approx. $2 \mathrm{~mm}$. Samples were bended on the three-point stand by using Instron testing machine and the "Ins $K_{I c}$ " software. The loading force as a function of displacement (that represents opening the crack edges) was recorded. The tests were terminated after breaking a sample. Each variant of this study represent three samples.
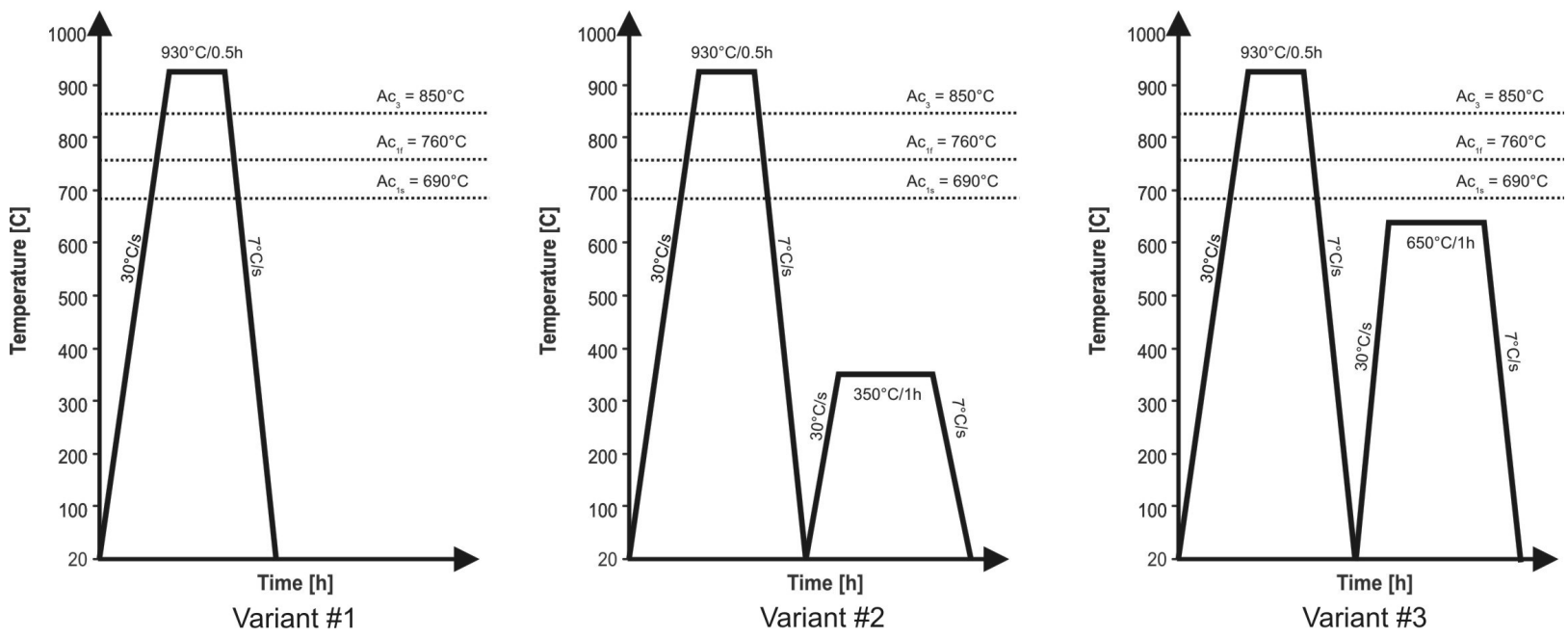

Fig. 1. Schematic representation of the heat treatment operations

\section{Results and discussion}

Results of the microstructure examination of the material in as-cast (raw) state are shown in our previous paper [15]. It was reported that a slow cooling rate of the cast during its solidification process gives a bainite structure (Fig. 2a,b).

As it is found in Fig. 2c,d a cooling of the steel after the normalization, from the temperature of homogeneous austenite $\left(930^{\circ} \mathrm{C}\right)$ to room temperature leads to its retransformation into the bainitic structure (Fig. 2c). Due to a non-uniform intensity of chemical etching, a local segregation sites formed upon the crystallization may be observed in the microstructure (Fig. $2 \mathrm{~d}$ ). A presence of bright areas along grain boundaries of the former austenite is related to an increased quenching rate after the applied normalization treatment. The rapid quenching of these areas (that are enriched with carbon and alloying additives) suppresses a precipitation of carbides. In these boundaries regions the $M_{S}$ value is lowered, what results in maintaining a greater amount of the retained austenite. A slower cooling leads to a carbides precipitation from the bainitic ferrite, giving in turn a depletion of carbon in the primary austenite boundaries (Fig. 2c). Beside of the bainitic structure, a small amount of martensite is also observed in the segregation sites (Fig. 2d). The formation of small amount of martensite is associated with a higher quenching rate of the laboratory samples, as compared to the massive casting. The microstructure of the steel after $1 \mathrm{~h}$ tempering at $350^{\circ} \mathrm{C}$ (the variant \#2) is shown in Fig. 2e,f. The tempering at $350^{\circ} \mathrm{C}$ leads to a less pronounced segregation (Fig. $2 \mathrm{e})$. A bright network along grain boundaries of former austenite (that is a mixture of retained austenite and martensite) became smaller what points toward a start of transformation of the retained austenite into the tempered martensite). As a consequence of the tempering at $650^{\circ} \mathrm{C}$, a differentation of microstructure in the segregation sites and a disappearing of lamellar structure, was observed (Fig. 2g,h). The heat treatment conducted according to the variant \#3 (Fig. 2h) results in a full transformation 


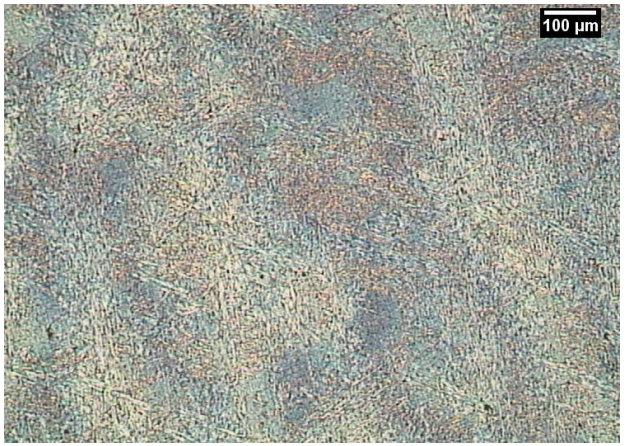

a)

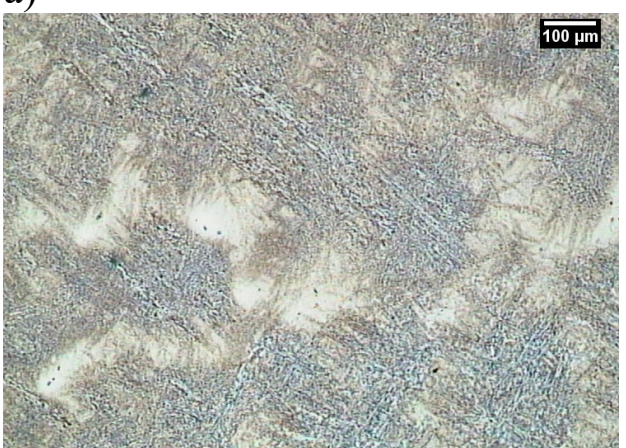

c)

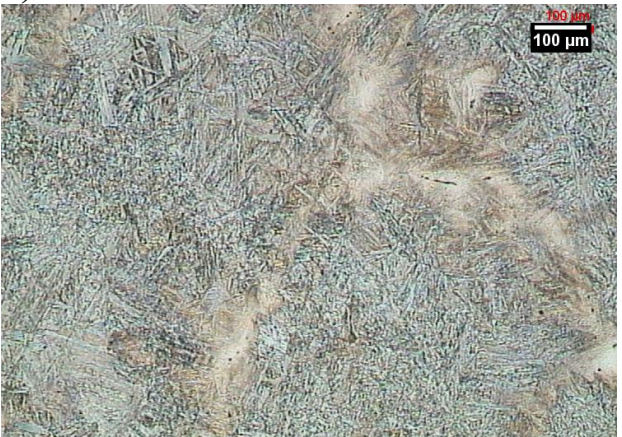

e)

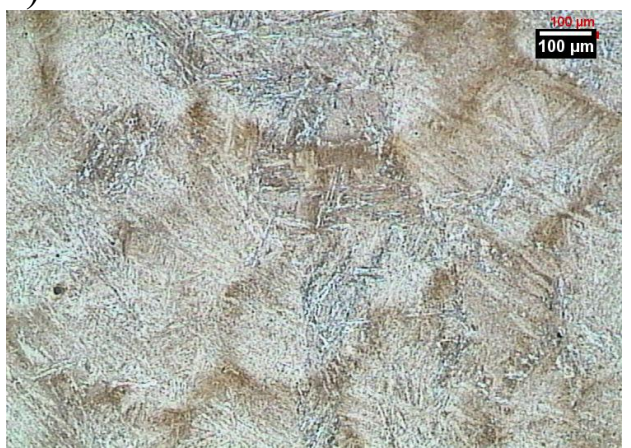

g)

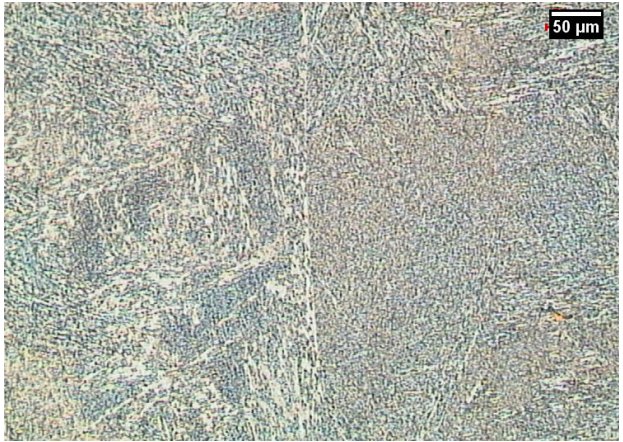

b)

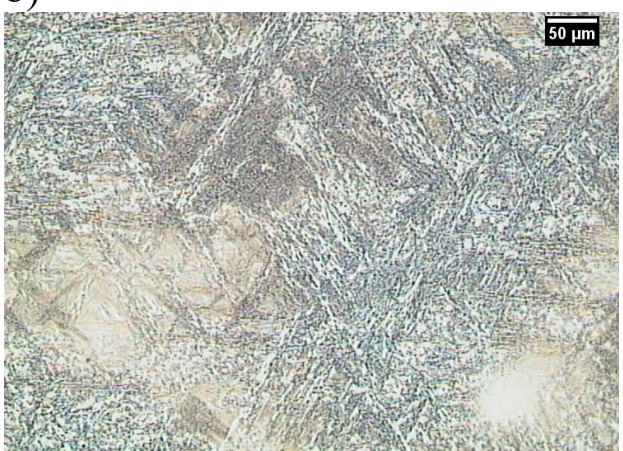

d)

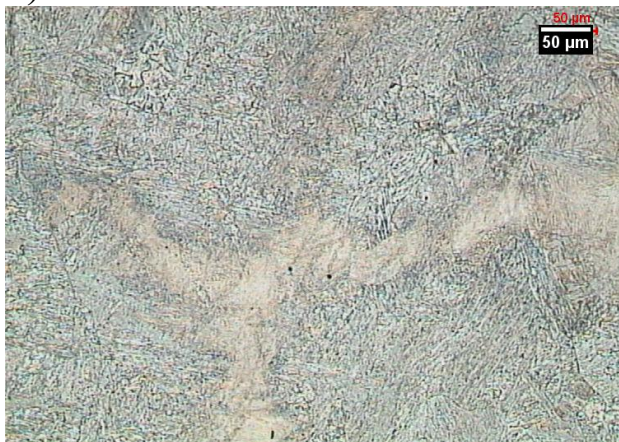

f)

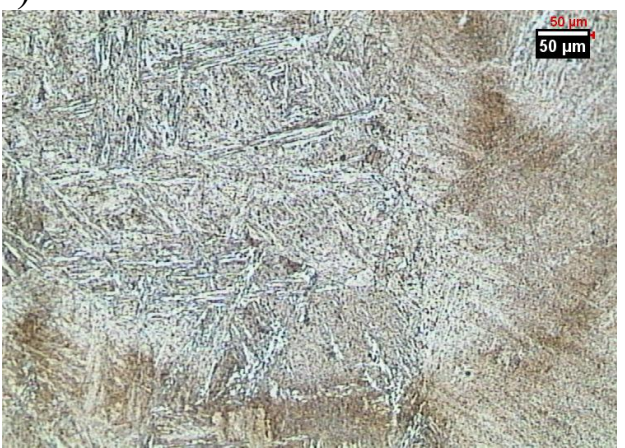

h)

Fig. 2. Light microscopy images showing the microstructure of the bainitic cast steel: a,b) as cast condition [15]; c,d) - after the variant \# 1; e,f) - after the variant \#2 g,h) - after the variant \#3

of the retained austenite and a tempering of martensite in the segregation sites. These findings are reflected with a lack of the bright network that was previously observed in the as normalized material. Moreover, the tempering at $650^{\circ} \mathrm{C}$ facilitates the occurrence of recrystallization phenomena, what should also significantly affects mechanical properties.

Results of the mechanical properties examinations of steel samples after each variant of applied heat treatment are listed in Fig. 2. In the previous paper [15] we showed results of the mechanical properties testing and XRD calculated fraction of retained austenite for the material in as cast condition. The cast steel in its initial condition was characterized by the hardness of 336 HV30. The material's hardness after the normalizing treatment increased to 366 HV30 (Fig. 3e). This hardness increase is associated with a formation of small amount of martensite along grain boundaries of the former austenite. Furthermore, 


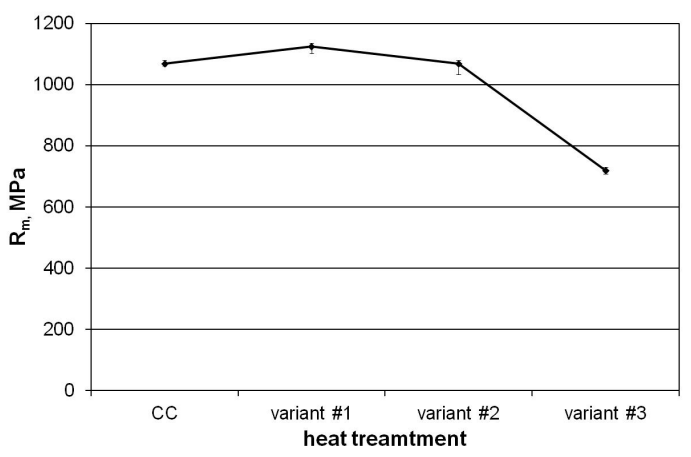

a)

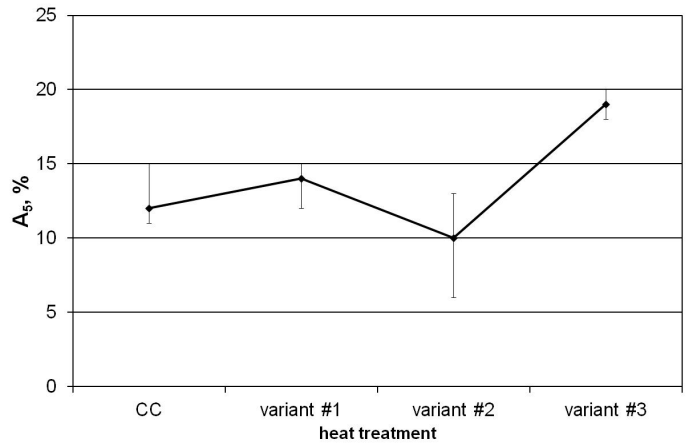

c)

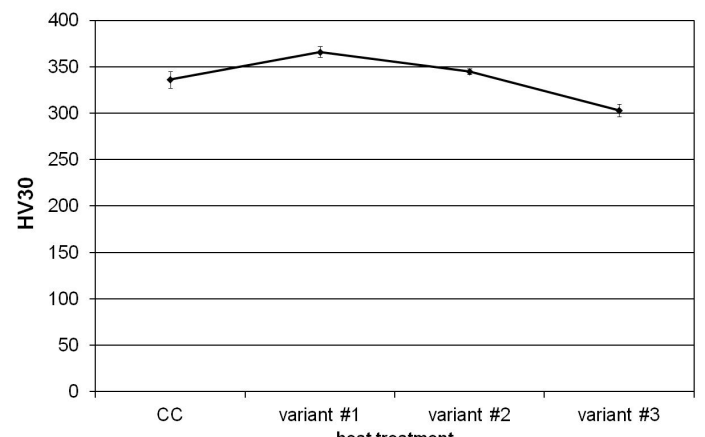

e)

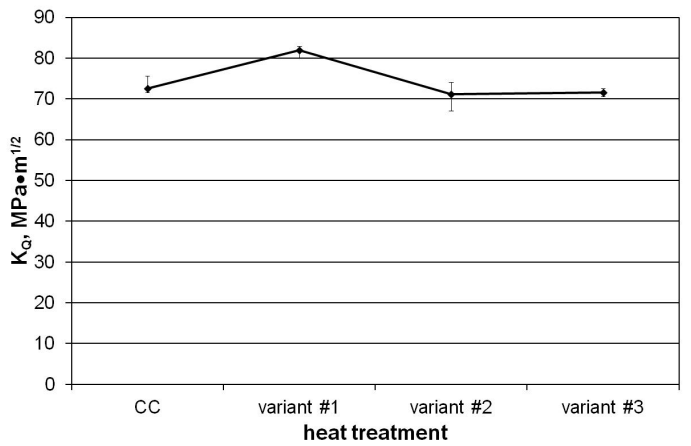

g)

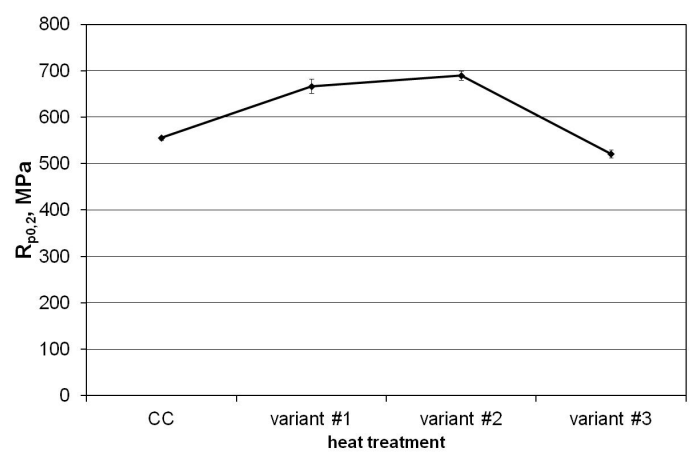

b)

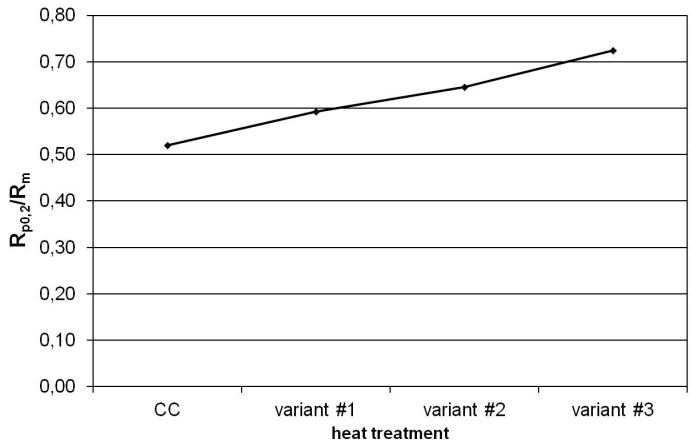

d)

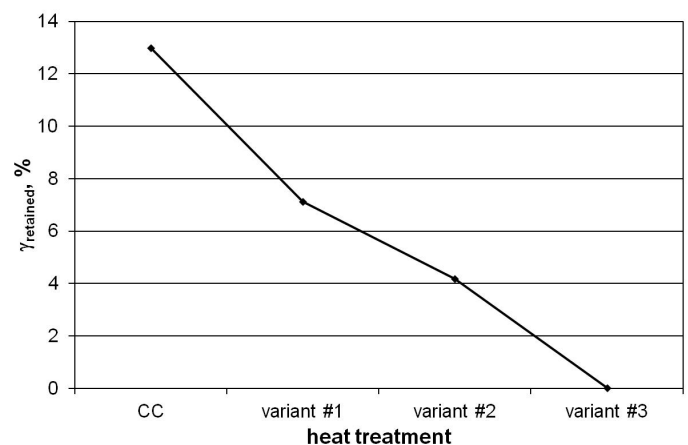

f)

ig. 3. The results of mechanical testing and XRD calculated fraction of retained austenite after different heat treatments

the normalization treatment leads to a significant improvement of the tensile strength (TYS $=667 \mathrm{MPa}$, UTS $=1125 \mathrm{MPa}$ ) and recorded elongation $\left(A_{5}=14 \%\right.$ ) (Fig. 3a-c).

The application of the heat treatment according to the variant \#2 did not prominently alter mechanical properties of the material as compared to those of as-normalized specimens, despite of a slight decrease of measured hardness. On the other hand, using of the additional tempering at $650^{\circ} \mathrm{C}$ (the variant \#3) gives a 35\% decrease of the UTS (that was $400 \mathrm{MPa}$ lower than that of the as-normalized material), $25 \%$ decrease of the 
TYS and 30\% decrease of hardness (Fig. 3a-c). This evolution of mechanical properties confirms a progress in the structure tempering. Simultaneously, the application of variant \#3 leads to almost 3-times higher impact toughness to that exhibited by materials subjected to the other treatments. The TYS/UTS ratio may be used as an indicator of the heat treatment efficiency (Fig. 3d) - its value close to 1 points toward a high efficiency. The retained austenite is partially transformed after the normalization, while a further annealing upon the tempering stage gives its complete transformation into tempered martensite (Fig. 3f).

It was found that the value of $\mathrm{K}_{\mathrm{Q}}$ parameter is only slightly affected by the applied heat treatment (it was generally approx $70 \mathrm{MPa} \times \mathrm{m}^{1 / 2}$ for all samples, except the variant \#1 which was approx. $80 \mathrm{MPa} \times \mathrm{m}^{1 / 2}$ ). This measurable increase of fracture toughness due to applying the variant \#1 of heat treatment should be probably related to a better mechanical stability of the retained austenite than that of as-cast samples.

It is especially worth noted that the investigated cast steel even in its initial condition was characterized by the fracture toughness twice higher than that required for railway applica- tions $\left(29 \mathrm{MPa} \times \mathrm{m}^{1 / 2}\right)$. Neverthelss, only the variant \# 3 of heat treatment results with the changeover from the brittle to ductile fracture type (Fig. 4d).

\section{Conclusions}

Critical temperatures $\left(A c_{1 s}, A c_{1 f}, A c_{3}\right)$ were estimated by dilatometric methods, what allowed setting correct parameters of heat treatments. The heat treatment (by the variants \#2 and \#3) leads to a stabilization of retained austenite in grain boundaries area of the primary austenite. Additionally, the heat treatment according to the variant \#3 results with an almost 3-times higher impact toughness to that exhibited by materials subjected to the other treatments. A high inhomogeneity of chemical composition in the as-cast bainitic steel leads to a prominent fraction of the retained austenite after the normalization, and its further annealing induces a transformation to tempered martensite. The proposed tempering treatment has a beneficial impact on mechanical properties, what is reflected by increased values of the TYS/UTS ratio.

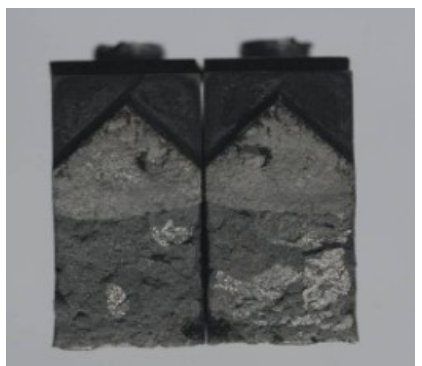

c)

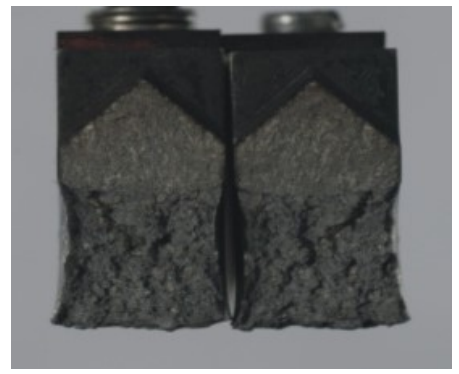

d) b)

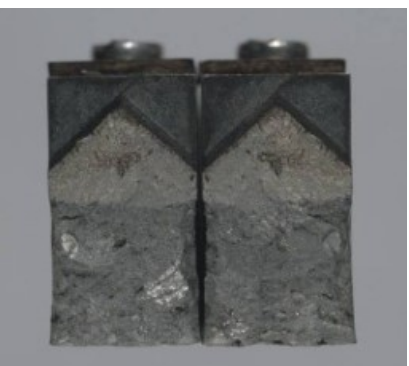

Fig. 4. Macroscopic photographs of the fracture surface cracking resistance test for different variants of heat treatment: a) as cast condition, b) variant \#1, c) variant \#2, d) variant \#3

\section{REFERENCES}

[1] M. Hotzman, I. Dlouhy, J. Zboril, Hutnicke Listy 58, 8-20 (2003).

[2] D. Korab, Railway Review 131, 89-92 (2000).

[3] J. Pacyna, J. Krawczyk, Metallurgy and Foundry Engineering 27 (2), 229-235 (2001).

[4] H.A. Aglan, Z.Y. Liu, M.F. Hassan, M. Fateh, Journal of Materials Processing Technology 151, 268-274 (2004).

[5] J. Pacyna, The first Polish bainitic rails, Polish Metallurgy in years 2002-2006, Committee of Metallurgy of The Polish Academy of Science, 651-656 (2006).

[6] F.C. Robles Hernández, N.G. Demas, D.D. Davis, A.A. Polycarpou, L. Maal, Wear 263, 766-772 (2007).

[7] K.M. Lee, A.A. Polycarpou, Wear 259, 391-399 (2005).

[8] P. Clayton, Wear 191, 170-183 (1996).
[9] J. Pacyna, P. Bała, IV Nationwide Scientific - Technical Conference ,Welding railways - the quality, reliability, safety” Bochnia (2010).

[10] J. Pacyna, T. Skrzypek, Archives of Foundry Engineering 8, 111115 (2008).

[11] R.K. Steele, Report of the Federal Railroad Administration, Washington, D.C. (2002).

[12] F.C. Zhang, C.L. Zheng, B. Lv, T.S. Wang, M. Li, M. Zhang, Engineering Failure Analysis 16, 1461-1467 (2009).

[13] D.R. Pendelton, K. Compton, E.G. Jones, Railway Gazette International, 3 (1986).

[14] M.R. Green, W.M. Rainforth, M.F. Frolish, J.H. Beynon, Wear 1-6, 756-765 (2007).

[15] S. Parzych, E. Tasak, Archives of Foundry Engineering 10, 113116 (2010). 